\title{
Data analysis and tools applied to modeling and simulation of a PV system in Ecuador
}

\section{(Análisis de datos y herramientas aplicadas al modelado y simulación de un sistema fotovoltaico en Ecuador)}

\author{
D. J. Benavides¹, F. Jurado², L. G. González³
}

\begin{abstract}
:
This paper presents a research that was carried out for the management of a photovoltaic system in a Microgrid, with applications and the use of tools applied to modeling and computational simulation in the Microgrid laboratory implanted in the facilities of the University of Cuenca (Ecuador). Additionally, through the use of automatic learning techniques, the behavior of the photovoltaic system has been modeled in the study area based on radiation and temperature with very good results. In addition, several applications can be made in real engineering studies such as feasibility, performance analysis, energy estimation, educational models, etc.
\end{abstract}

Keywords: data analysis; modelling; simulation; photovoltaic; Matlab/Simulink.

\begin{abstract}
Resumen:
En el presente trabajo, se realizó una investigación para la gestión de un sistema fotovoltaico en un Microrred, con aplicaciones y el uso de herramientas aplicadas al modelado y simulación computacional en el laboratorio de Microrred implantado en las instalaciones de la Universidad de Cuenca (Ecuador). Además, mediante el uso de técnicas de aprendizaje automático, el comportamiento del sistema fotovoltaico se ha modelado en el área de estudio en función de la radiación y la temperatura con muy buenos resultados. Además, se pueden realizar varias aplicaciones en estudios de ingeniería reales, como la viabilidad, el análisis del rendimiento, la estimación de la energía, los modelos educativos, etc.
\end{abstract}

Palabras clave: análisis de datos; modelado; simulación; fotovoltaico; Matlab/Simulink.

\section{Introduction}

Technology's progress of renewable energies in recent years has marked an impressive development for the generation, transmission and intelligent distribution of electric energy. Achieving an economic benefit for the user and its correct management for development. In addition, with the implementation of Information and Communication Technologies (ICTs), Electric Power Systems (EPS) will develop into Smart Grids (SG), more flexible, cleaner, safer and more economical. This study makes the implementation of a photovoltaic energy estimator of a Microgrid (MG), consisting of a set of 160 panels with nominal capacity of $35 \mathrm{kWp}$, distributed as follows: $15 \mathrm{~kW}$ array of monocrystalline panels, polycrystalline $15 \mathrm{~kW}$ and polycrystalline $4 \mathrm{~kW}$ with tracking in an axis, Espinoza et al. (2017), the study is carried out with the MATLAB® Simulink tool. Therefore, the behavior of the system can be modeled by the use of computational tools as in the studies in: Prasanth et al. (2018); Razman and Chee, (2017); Rameen, (2017); Ahmad et al. (2017). This allows to have a referential system with respect to the installed to estimate the production of energy under the available solar resource, also allows to study the possibility of improving the

\footnotetext{
1 University of Jaén, Jaén, España (djbp0001@red.ujaen.es).

2 University of Jaén, Jaén, España (fjurado@ujaen.es).

${ }^{3}$ University of Cuenca, Cuenca, Ecuador (luis.gonzalez@ucuenca.edu.ec).
} 
performance by replacing new panels with superior characteristics. The design criteria have been referred to the technical specifications of the panels and equipment installed. To obtain its validation by means of measurement tests in each stage, a database obtained from the weather station and a comparison of the real measurements with the results of the model have been entered.

\section{Description of the photovoltaic system}

The photovoltaic system about study is located in the Balzay Technological Campus of the University of Cuenca in Ecuador, latitude: -2.892, longitude: -79.038 , time: GMT-5, azimuth: $196.54^{\circ}$. This system has a nominal capacity of $35 \mathrm{kWp}$ consisting of 136 photovoltaic solar panels of $250 \mathrm{Wp}$ each, Atersa brand (Spain), distributed as follows: Photovoltaic System 1 (PVS1) with 60 fixed panels oriented at an angle of $5^{\circ}$ north of monocrystalline type with a capacity of $15 \mathrm{~kW}$; PVS2 with 60 fixed panels oriented at an angle of $5^{\circ}$ north of polycrystalline type capacity of $15 \mathrm{~kW}$, both sub groups contain a GPTech independent two-level inverter with tracking of the maximum power point. In addition, there is a PVS3 with 16 panels, $4 \mathrm{kWp}$ capacity, of polycrystalline type, movable on an axis with east-west tracking capability with a maximum inclination of $90^{\circ}$. The mobile photovoltaic system is connected to an inverter with a nominal capacity of $5 \mathrm{~kW}$ of Fronius Primo brand model 5.0-1, Espinoza et al. (2017). The Table 1 summarizes the photovoltaic system and its main characteristics:

Table 1. Characteristics of photovoltaic systems.

\begin{tabular}{|c|c|c|c|c|c|c|}
\hline $\mathbf{N}^{\circ}$ & Description & Panels & Model & $\begin{array}{c}\text { Max. } \\
\text { Current }\end{array}$ & $\begin{array}{c}\text { Max. } \\
\text { Voltage }\end{array}$ & $\begin{array}{c}\text { Max. } \\
\text { Power }\end{array}$ \\
\hline 1 & PVS1 & $\begin{array}{c}60(15 \times 4) \\
\text { Series-parallel }\end{array}$ & $\begin{array}{c}\text { Atersa } \\
\text { A-250P }\end{array}$ & $35.78 \mathrm{~A}$ & $553 \mathrm{~V}$ & $15 \mathrm{~kW}$ \\
\hline 2 & PVS2 & $\begin{array}{c}60(15 \times 4) \\
\text { Series-parallel }\end{array}$ & $\begin{array}{c}\text { Atersa } \\
\text { A-250M }\end{array}$ & $35.04 \mathrm{~A}$ & $563 \mathrm{~V}$ & $15 \mathrm{~kW}$ \\
\hline 3 & PVS3 & $\begin{array}{c}16(16 \times 1) \\
\text { Series-parallel }\end{array}$ & $\begin{array}{c}\text { Atersa } \\
\text { A-250P }\end{array}$ & $8.94 \mathrm{~A}$ & $598 \mathrm{~V}$ & $4 \mathrm{~kW}$ \\
\hline
\end{tabular}

\section{Methodology}

The procedure and the methodology used for the estimation of energy from the photovoltaic system about study is carried out through modeling and simulation mainly in 4 stages, which are: data acquisition, modeling and simulation, validation and finally applications, as observed in Figure 1:

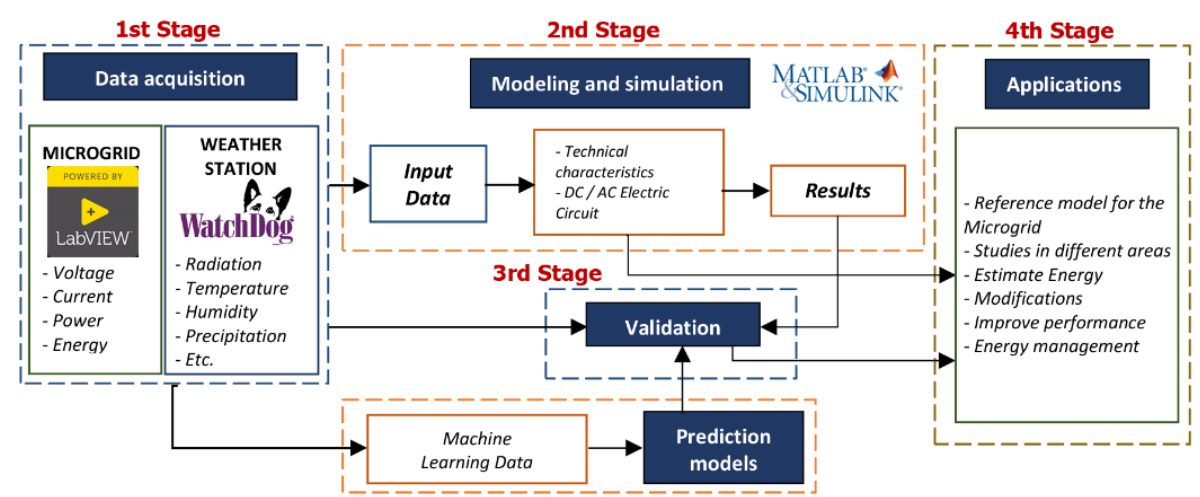

Figure 1. Scheme for the estimation of energy of the photovoltaic system 


\subsection{First Stage - Data Acquisition}

The data acquisition was developed in two sections: Meteorological data Radiation $\left[\mathrm{W} / \mathrm{m}^{2}\right]$ and temperature $\left[{ }^{\circ} \mathrm{C}\right]$ obtained directly from the WatchDog 2000 Series Weather Station and Microgrid data including: voltage, current, power and energy, both in Direct Current DC and $A C$ alternate, through the electrical variable measuring equipment HIOKI PW3337 (see Figure 2), with the help of a graphical and storage interface designed in LabVIEW and a TCP/IP LAN connection. The sample size of the measurements was executed for each minute during each day of operation $6 \mathrm{am}-6 \mathrm{pm}$, for the two sections simultaneously, during a monitoring period of 4 months.

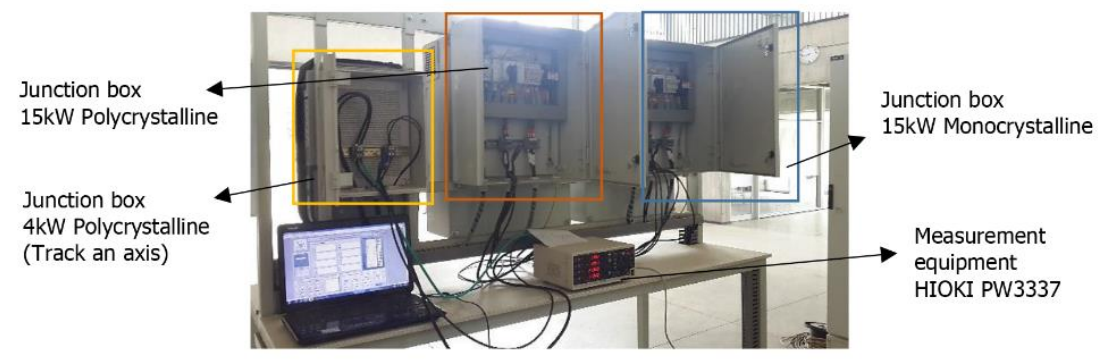

Figure. 2. Acquisition of data from the Microgrid HIOKI PW3337 - LabVIEW

\subsection{Second stage - Modeling and simulation}

In this stage of the methodology the main aspects have been considered, a database of meteorological resources with radiation and non-uniform temperature, see example: Ding et al. (2012) and Sreenivasa et al. (2017), electrical system, tracking algorithms Perturb and Observe, Nayak and Shaw, (2017); and finally the 3D modeling of the tracking component. From the data coming from the weather station, the modeling and simulation of the three photovoltaic generation systems (fixed monocrystalline, fixed polycrystalline and axis tracking) were designed, using the MATLAB Simulink tools, see: Rameen, (2017) and Ahmad et al. (2017). In this application a so-called "PV Array" of a series of photovoltaic modules was used, where it is selected from a wide list of models and manufacturers.

The model corresponding to the photovoltaic system about study, is represented in Figure 3, where the model made in Simulink of MATLAB can be observed, which includes a database of radiation and temperature of the weather station in "xlsx" format, the PV Array block with the specifications of the Atersa A250P and A250M models, in the respective parallel series configuration and the implementation of the MPPT with the Perturb and Observe algorithm of MATLAB. A three-phase DC/AC inverter "Average-model based VSC" with a switching frequency of $5 \mathrm{kHz}$ is used for the interconnection to the AC system and they function as current sources to the PCC (Point Coupling Common). For the connection to grid, a galvanic isolation using dry type three-phase $400 \mathrm{~V} / 230 \mathrm{Vac}$ transformers is used, and the simulation of the system was developed with a configuration where a constant load of $30 \mathrm{~kW}$ can be fed into the PCC from the photovoltaic system about study or from the public electric power system, which has a transformer with a capacity of 150kVA to $12.7 \mathrm{kV}$ from the public grid, in representation of the laboratory facilities of the University of Cuenca. 


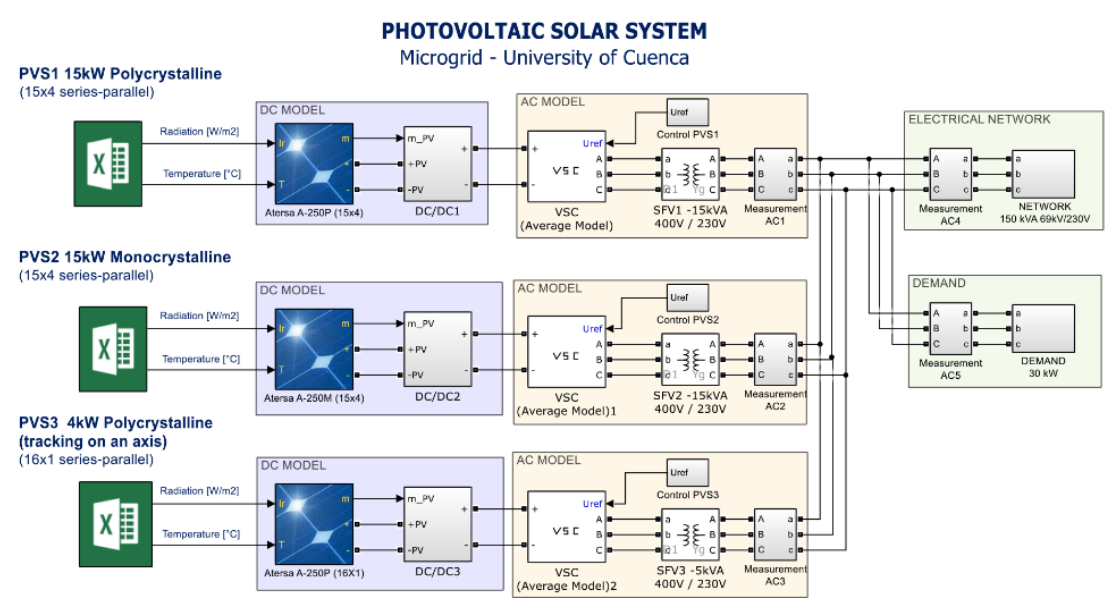

Figure 3. Modeling of the Photovoltaic System

For modeling of the photovoltaic solar panels, the behavior is used by the curves I$\mathrm{V}, \mathrm{P}-\mathrm{V}$ from the libraries obtained from MATLAB, the photovoltaic systems are studied at a constant temperature of $25^{\circ} \mathrm{C}$. Figures $4 a$ and $4 b$ show a similarity in the ranges of current and voltage operation between polycrystalline and monocrystalline models, under the different solar radiation conditions. In the characteristics I-V, P-V Polycrystalline 4kW Photovoltaic System tracking on a Figure $4 c$ axis the range of voltage operation increases when considering 16 panels in series, with respect to previous systems and its current is limited to $8.94 \mathrm{~A}$. From the figure it is observed that to operate at the point of maximum power, in the case of polycrystalline it is necessary to operate near 450V with a variation of $8 \mathrm{~V}$ in the case of decreasing solar radiation to $400 \mathrm{~W} / \mathrm{m}^{2}$, monocrystalline with a value close to $460 \mathrm{~V}$ and a variation of $4 \mathrm{~V}$, finally polycrystalline with tracking on an axis in $480 \mathrm{~V}$ with a variation of $9 \mathrm{~V}$.
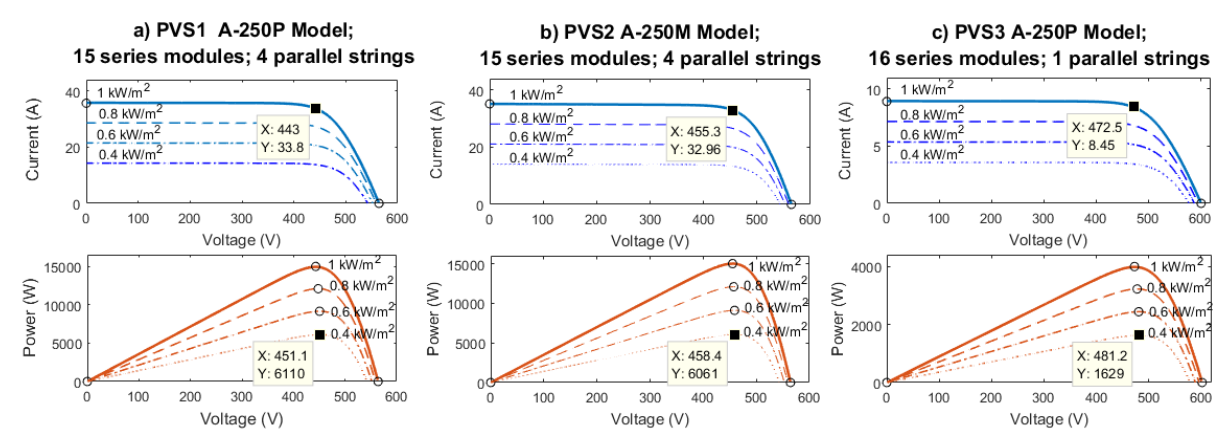

Figure 4. Characteristics I-V, P-V Photovoltaic Systems, models A-250P and A-250M

For graphically observe the tracking behavior on an axis, the V-Realm Builder MATLAB tool is used, which allows a $3 D$ model that responds before different locations of the energy source. The tracking algorithm is presented in Figure 5, where variable " $\mathrm{C}$ " indicates the direction of motor rotation and vector of constant motion on the axis MOV $=[1$ 0 0] $(x, y, z)$. 

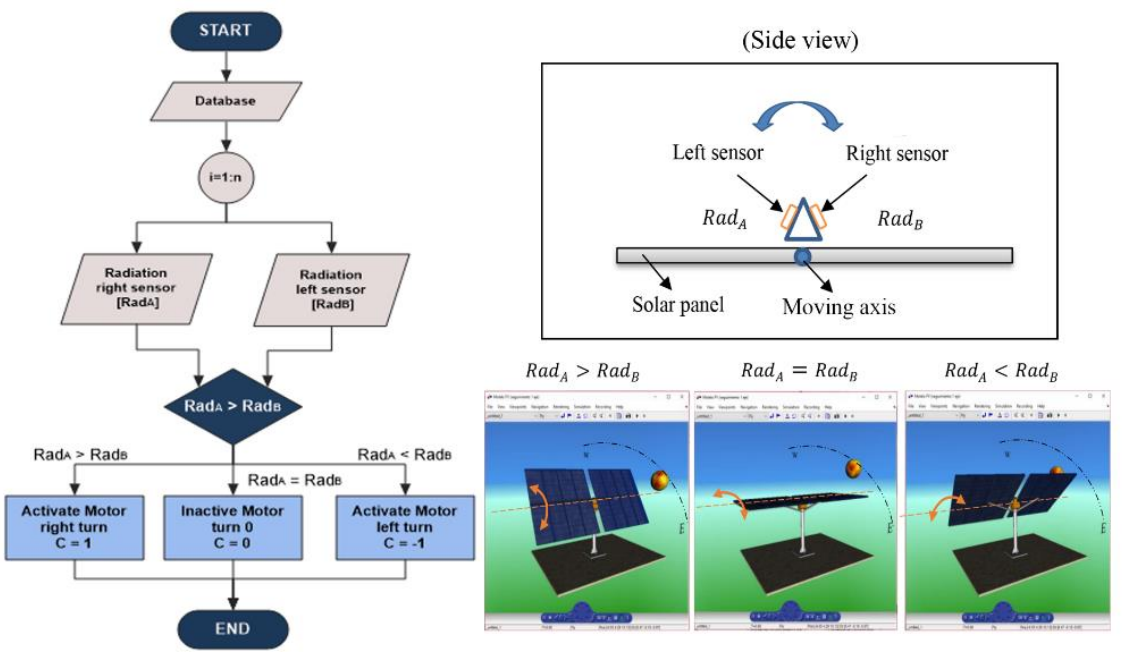

Figure 5. Flow chart tracking algorithm on an axis

Results of the Simulation:

In order to validate the proposed models, the data obtained from the weather station (WatchDog 2900ET) located in the study area were used and correspond to one day, the values of direct solar radiation are represented in $\left[\mathrm{W} / \mathrm{m}^{2}\right]$ and temperature in $\left[{ }^{\circ} \mathrm{C}\right]$. Figure 6 , shows the data obtained on the day (03/10/2018) between 6:00 a.m. to 6:00 p.m. As can be seen in the figure, there is an important variation close to 12:00 as a result of the frequent cloudiness of the area with a maximum radiation of $973 \mathrm{~W} / \mathrm{m}^{2}$ for an ambient temperature of $16.2^{\circ} \mathrm{C}$ and an average of $15.6^{\circ} \mathrm{C}$ during that day, temperature that within the model used does not represent a significant decrease in the generation of energy, given that the panels used have a coefficient of power of the temperature of $-0.43 \% /{ }^{\circ} \mathrm{C}$.

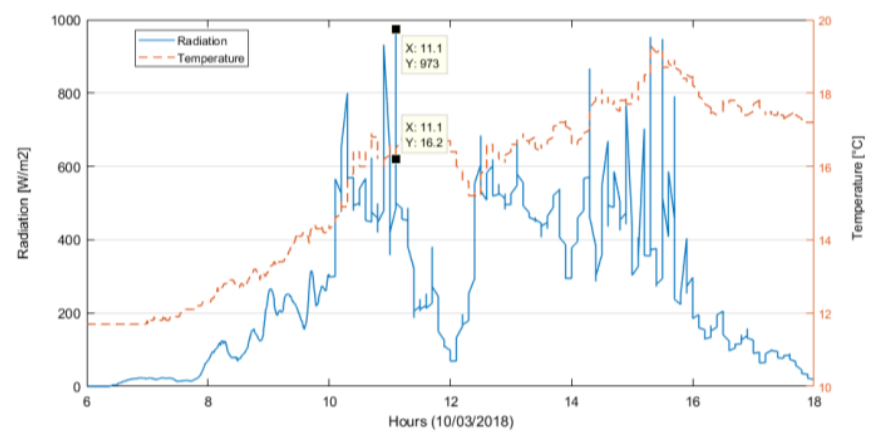

Figure 6. Input data model obtained from the weather station

From the meteorological data used, the behaviors of the designed photovoltaic models are presented in Figures $7 a$ and $7 b$, where the results of the instantaneous power and accumulated energy are shown. In them you can see a linear relationship between radiation and power generated. In Figure $7 \mathrm{c}$, the tracking system on one axis differs from the other systems, because the input data to the radiation model is the result of the tracking algorithm (see Figure 5), in this case it receives more solar radiation for its tracing.

In another aspect, Figure 8, the results of the energy in the output of the set of power converters in $\mathrm{AC}$ are observed, in it a linear relationship between the input power and the output current in AC is observed. It can also be seen that the PVS3 has a higher energy production comparatively around $11 \%$, which also reflects in the AC output of the inverter. 

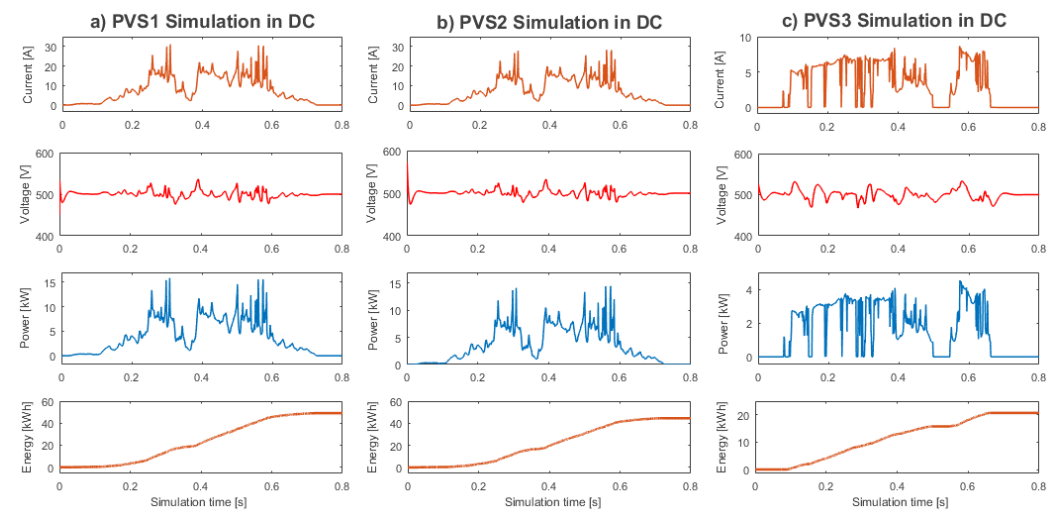

Figure 7. Energy behavior of the PVS1, PVS2 and PVS3 systems, in Direct Current

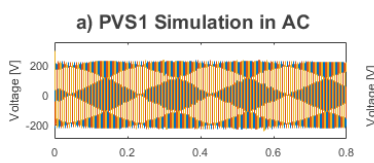

b) PVS2 Simulation in AC
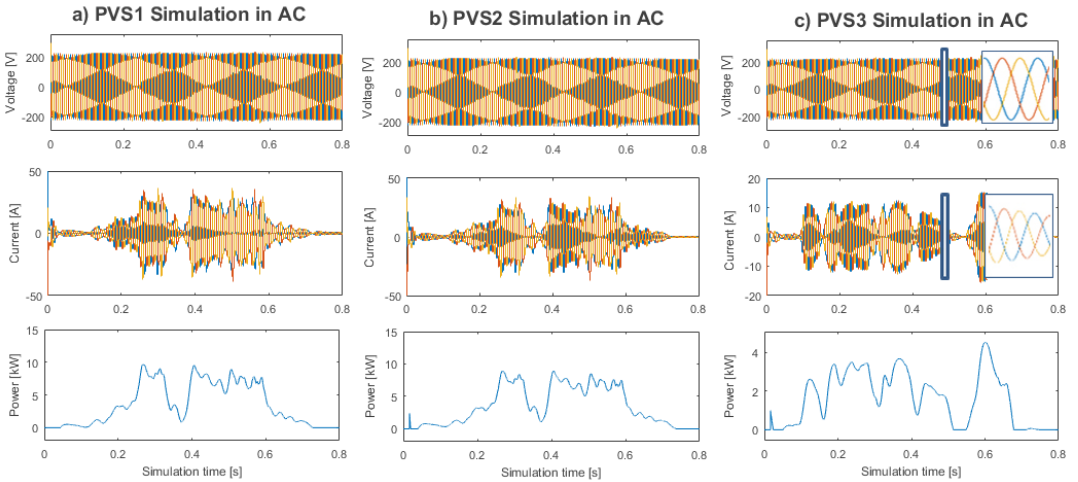

Figure 8. Energy behavior of the PVS1, PVS2 and PVS3 systems, in Alternate Current

\subsection{Third stage - Validation of results}

In the validation process of the model, the database of the Microgrid obtained in the first stage was used, together with the results of the simulation. For the process of validation of the results, the similarities of the model and the real data were analyzed, obtaining an approximation of $95 \%$ in each parameter. Next, the verification for the polycrystalline $15 \mathrm{~kW}$ system is presented and for the rest of the photovoltaic systems it has been carried out with the same procedure.

\section{Result and validation PVS1}

The operating range of the system, due to its configuration in 4 parallel strings, maintains its nominal current value at $35.78 \mathrm{~A}$ with a nominal irradiance of $1000 \mathrm{~W} / \mathrm{m}^{2}$ (see Figure $4 a$ ). The checking of the model current and actual measured current $D C[A]$ is presented in Figure 9a:
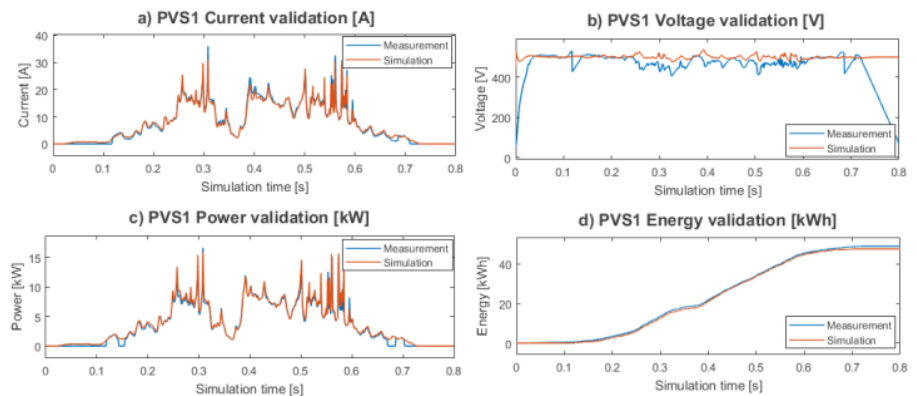

Figure 9. Simulation results and measurements 
On the other hand, the voltage covers an operating range between 400 to $500 \mathrm{Vdc}$. In Figure $9 b$ you can see the model voltage and real voltage reached in the photovoltaic system with the MPPT controller implementing the perturb and observe algorithm, in the figure it can be verified that MPPT operation range oscillates around 450Vdc as indicated by the Maximum power operating point of the array specifications (see Figure 4a). The power [kW] and the energy in [kWh] presented in Figure $9 c$ and $9 d$, respectively, show a great approximation with the measurement values.

In the verification of the tracking algorithm on an axis, an alternative database was used, which represents the values obtained from the measurement sensors of the two axes (right-left), see Figure 10a. In response to the algorithm, its performance can be observed at points where the radiation is greater as seen in Figure $10 b$.

a) Input data to the algorithm

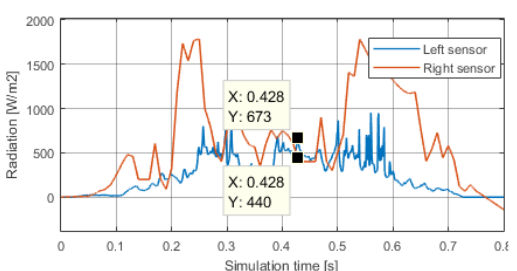

b) Motor activation simulation

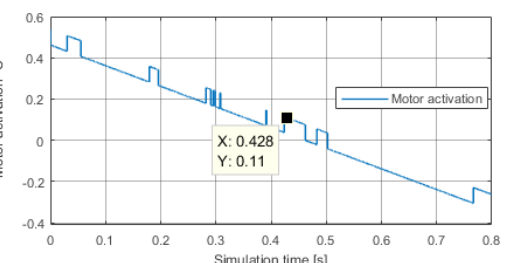

Figure 10. Results of the tracking algorithm on a $4 \mathrm{~kW}$ polycrystalline axis

\subsection{Automatic data analysis}

Advanced data analysis applications with functionality and versatility, allow managing the information of the electrical grid to analyze and extract information, for example: improving energy quality, more efficient distribution, optimization, machine learning, etc. Therefore, under this same criterion, the slogans are corrected as new information is known, see examples in: Chunming et al. (2017) and Mellit et al. (2009). Figure 11 shows the correlation matrix based on the Pearson correlation coefficient of the variables obtained from the weather station of the zone in the interval 10/02/2018 until $03 / 15 / 2018$, where the variable to be predicted (supervised learning) is the power of PVS1, depending on the other variables.

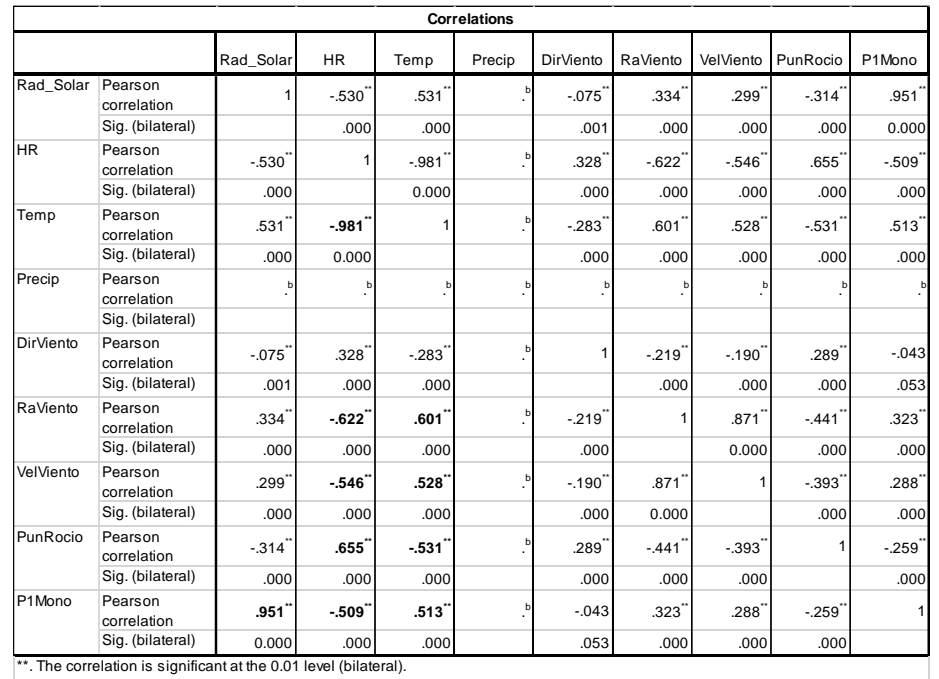

- Itcan nobecalod because, at least one of the variables is cosstant

Figure 11. Matrix of correlation of meteorological variables.

In the correlation matrix it can be seen that the variable of interest electric power (P1Mono) has a high correlation coefficient of 0.951 with respect to solar radiation (Rad_Solar) and a coefficient 0.513 with the temperature variable (Temp), plus a coefficient inversely proportional to the variable relative humidity $(H R)-0.509$, therefore the most 
significant variables for the study represent solar radiation and one of the two variables: temperature or relative humidity, since these variables are inversely related in -0.981 . On the other hand, the variables Precipitation (Precip), Wind speed (VelViento), Direction (DirViento), Gust of the wind (RaViento) and Dew point (PunRocio) do not influence to a great extent the variable of interest, therefore they are not considered in the model.

\section{Linear Regression Model Monocrystalline System}

When applying the linear regression algorithm with a database in $70 \%$ training percentage and $30 \%$ in validation in the computer program Waikato Environment for Knowledge Analysis (WEKA), a correlation coefficient was obtained in $94.79 \%$ of the regression model and an absolute relative error of $19.21 \%$. Equation 1 represents the power $[\mathrm{W}]$ according to the most significant variables of the analysis in the area: radiation $\left[\mathrm{W} / \mathrm{m}^{2}\right]$ and temperature $\left[{ }^{\circ} \mathrm{C}\right]$.

$$
P_{\text {Mono }}=12.425 * \operatorname{Rad}_{\text {Solar }}+78.038 * \text { Temp }-840.298
$$

In Figure 12a, the relationship between temperature, radiation and power variables is shown through a linear smoothing regression model. You can see its linear relationship of power with radiation in Figure 13a. The results of the model applying Equation 1 are shown in Figure 12b.
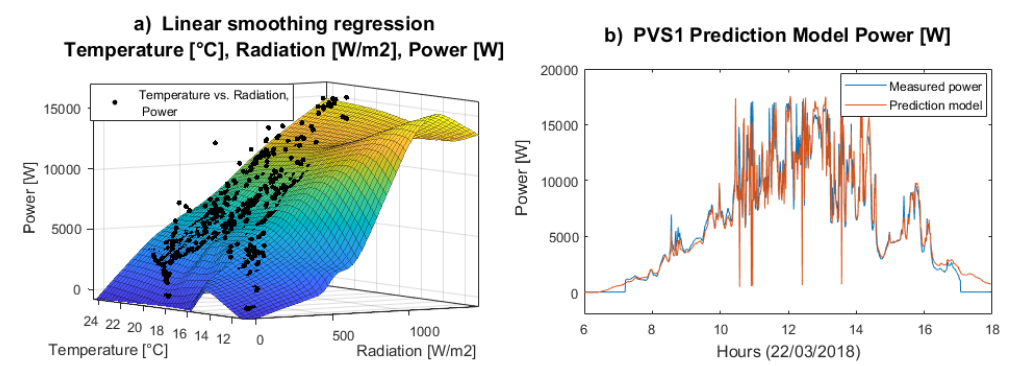

Figure 12. Linear regression model PVS1 supervised learning (70/30)

In order to observe the influence of the temperature variable with respect to the power in the study area comprised between $10^{\circ} \mathrm{C}$ to $25^{\circ} \mathrm{C}$, the smoothed spline model with a value of $p=0.95$ is included. The smoothed spline " $s$ " is presented in Equation 2, and is built for the smoothing parameter " $p$ " and the specified weights "wi" of MATLAB.

$$
p \sum_{i} w_{i}\left(y_{i}-s\left(x_{i}\right)\right)^{2}+(1-p) \int\left(\frac{d^{2} s}{d x^{2}}\right)^{2} d x
$$

In Figure 13b, the incidence of temperature for generation in PVS1 is observed, despite having a temperature between $10^{\circ} \mathrm{C}$ to $25^{\circ} \mathrm{C}$, most of the power values are lower than $6 \mathrm{~kW}$, which implies its dependence closer to solar radiation in similar climatic zones. Reason because, its correlation coefficient of 0.513 with the power has less influence with the radiation. 

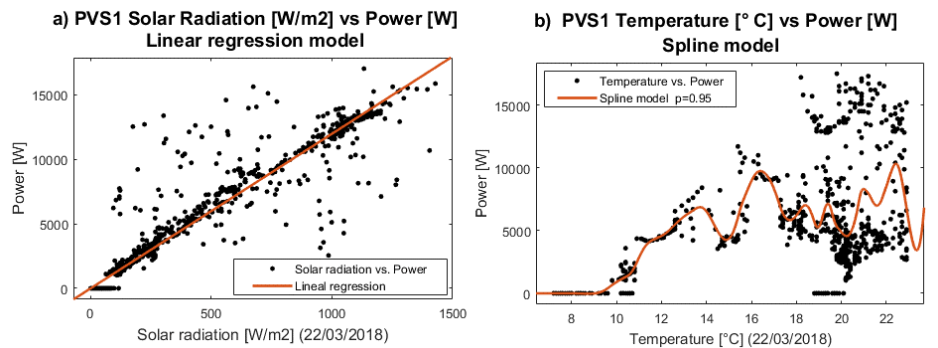

Figure 13. Incidence of radiation and temperature in the power of the PVS1

\section{Radiation Prediction}

Radiation data have an important impact on the generation of energy, Incidence of radiation and temperature in the power of the PVS1 which is why their prediction studies are developed in the field of Artificial Neural Networks (ANN), due to their degree of complexity and uncertainty, based on some applications: Meenal and Selvakumar, (2018); Almorox and Hontoria, (2014); and Almaraashi, (2018). Due to the scope of this 4-month study, your data is limited for the analysis at this point for the time being, for the application of these prediction models, but an example has been developed in the Figure 14, where the objective is to obtain a prediction model of solar radiation the next day (RadSolar2) from the meteorological data of the previous day.

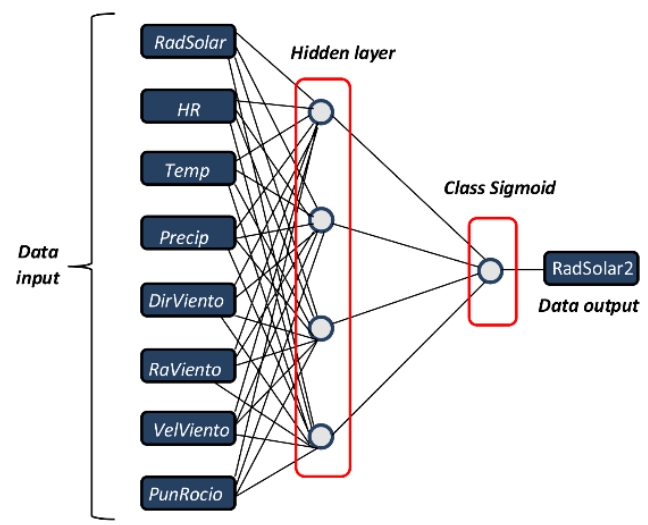

Figure 14. Example of artificial neural network model

\section{Temperature Prediction}

Applying the sum of sine model in a database through MATLAB (Figure 15a), where its objective is to determine an approximation of the temperature variable of the following day $f($ temp), through a learning of temperature data of the previous day (temp) in the same pre-established order. The results are obtained from the following Equation 3:

$$
\begin{gathered}
f(\text { temp })=345.8 \sin (0.1705 \cdot \text { temp }-0.712)+332.8 \sin (0.1761 \cdot \text { temp }+2.367)+ \\
1.222 \sin (1.02 \cdot \text { temp }-3.601)
\end{gathered}
$$

Figure $15 b$ shows the application of the model in a database and its results. The relative error is $10.34 \%$ of a 3 -day continuous test of the example in the study area. 

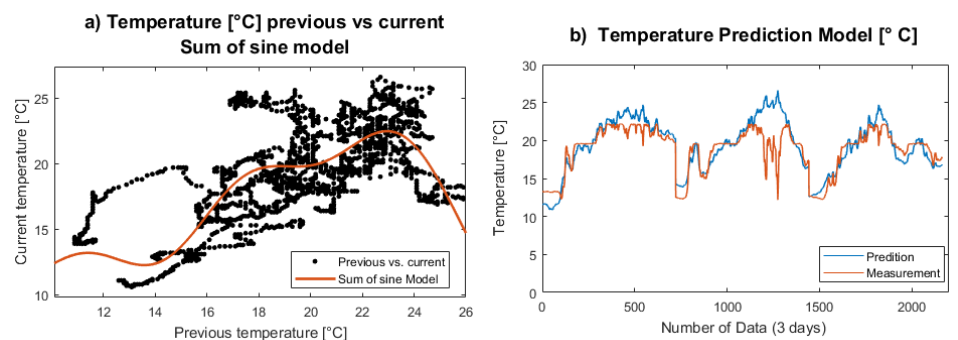

Figure 15. Ambient temperature prediction model

\subsection{Fourth stage - Application of the model}

In order to use the referential model for the Microgrid using the modeling tools used, it is possible to carry out applications where the feasibility of photovoltaic installations is studied in places where radiation and temperature meteorological data are known, as well as the type of solar panel photovoltaic selected. When obtaining a model you can also make changes and study the possibilities of improving the current system, such as changing and testing different models of the panel manufacturers intuitively, replacing the panels with greater power generation, studying the possibility of changing a fixed system in tracking on an axis, etc. As an example, if we study the possibility of changing the $15 \mathrm{~kW}$ fixed polycrystalline system in a system with tracking on an axis, as a result we obtain that for a fixed system on average in a day of analysis (03/10/2018), 6.375kW were generated, when changing the fixed system in tracking on an axis, an average of $7.075 \mathrm{~kW}$ is obtained, which guarantees an increase of approximately $11 \%$ on that day.

\section{Development of graphical user interface GUI}

A graphic interface has been developed for the user in the MATLAB GUIDE application so that they can observe and interact intuitively, see an example in: Bays et al. (2014). The program has an application for educational purposes later, where you can load a database and estimate the energy production of the study. Besides, it offers the possibility of making modifications to the parallel serial connections of the system and choosing different manufacturers (see Figure 16).
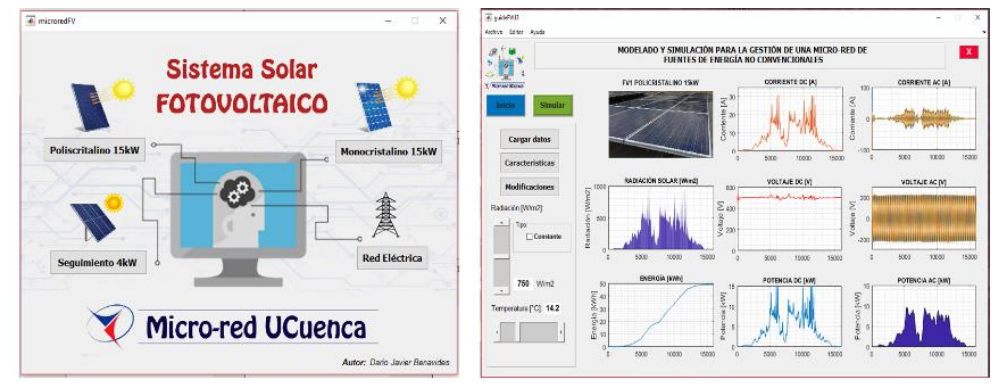

Figure 16. Main Application and Graphic Interface GUIDE -MATLAB

\section{ICTs applied to energy management}

The Microgrid is an effective means for an active distribution grid, which will help the large-scale integration and transition from the traditional grid to the smart grid. Similarly, the control and monitoring system, plus information and communication technology, together create "Smart Cities", which facilitates the supervision and control of electric energy transport. In this sense, electrical services are involved in grid automation processes, supported by ICTs, to improve grid efficiency, reliability, security and quality of service (see Figure 17). 


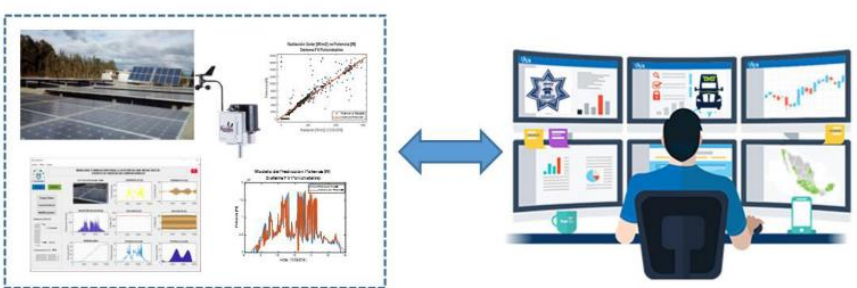

Figure 17. Energy management through models

\section{Conclusions}

Using tools for modeling and simulation, we have been able to observe the behavior of the different elements of the photovoltaic generation that participate in the Microgrid, with results similar to their original behavior. The measurement error with respect to the model is less than $4 \%$, which guarantees an excellent reference for the modeled system. Some basic equipment specifications have been directly related to the model, although other factors that alter their normal behavior must also be considered. The use of values and real data can be approximated to a large extent to a real model, observing its most influential parameters and values implies a better knowledge in the study area.

Therefore, the implementation of ICTs in electrical systems allow us to improve the management of the electrical grid, as well as some techniques in the automatic learning of data in the prediction of some variables of interest. As a result of the modeling, some advantages can be highlighted, such as the dimensioning of the equipment, observing and controlling the abnormal effects, controlling the connection of the systems in their stationary state, analyzing the potential and performance of the equipment's, etc.

\section{References}

Ahmad, A., Mehdi, F., Pourya, S. and Cihan, H. (2017), Modeling and Simulation of Microgrid, Procedia Computer Science, 114, 392-400.

Almaraashi, M., (2018), Investigating the impact of feature selection on the prediction of solar radiation in different locations in Saudi Arabia, Applied Soft Computing, 66, 250263.

Almorox, J. and Hontoria, C., (2014), Global solar radiation estimation using sunshine duration in Spain, Energy Conversion and Management, 45, 1529-1535.

Bays, N., Clifton, J. and Hatipoglu, K., (2014), MATLAB-Graphical User Interface to study partial shading of PV array characteristics, IEEE SOUTHEASTCON, 1-4.

Chunming, T., Xi, H., Zhikang, S. and Fei, J., (2017), Big data issues in smart grid - A review, Renewable and Sustainable Energy Reviews, 79, 1099-1107.

Ding, K., Bian, X., Liu, H. and Peng, T., (2012), A MATLAB-Simulink-Based PV Module Model and Its Application Under Conditions of Nonuniform Irradiance, IEEE Transactions on Energy Conversion, 27, 864-872.

Espinoza, J. L., González, L. G., and Sempértegui, R., (2017), Micro grid laboratory as a tool for research on non-conventional energy sources in Ecuador, IEEE International Autumn Meeting on Power, Electronics and Computing (ROPEC), 1-7.

Meenal, R. and Selvakumar, A., (2018), Assessment of SVM, empirical and ANN based solar radiation prediction models with most influencing input parameters, Renewable Energy, 121, 324-343.

Mellit, A., Kalogirou, S.A., Hontoria, L. and Shaari, S., (2009), Artificial intelligence techniques for sizing photovoltaic systems: A review, Renewable and Sustainable Energy Reviews, 13, 406-419.

Nayak, B. P. and Shaw, A., (2017), Design of MPPT controllers and PV cells using MATLAB Simulink and their analysis, International Conference on Nascent Technologies in Engineering (ICNTE), 1-6. 
Prasanth, J., Himanshu, M., Dhanup, S., Sudhakar, T., Masafumi, M. and Rajasekar, N., (2018), Analysis on solar PV emulators: A review, Renewable and Sustainable Energy Reviews, 81, 149-160.

Rameen, A., (2017), Modeling and simulation of a micro grid-connected solar PV system, Water Science, 31, 1-10.

Razman, A. and Chee, W. T., (2017), A comprehensive review on photovoltaic emulator, Renewable and Sustainable Energy Reviews, 80, 430-452.

Sreenivasa, G., Bramhananda, T. and Vijaya, M., (2017), A MATLAB based PV Module Models analysis under Conditions of Nonuniform Irradiance, Energy Procedia, 117, 974-983. 